\title{
Understanding vaccine hesitancy among mothers: the case of a community hit by rubella outbreak
}

\author{
Rhea Jenny A. Ogalesco ${ }^{1}$, Editha G. Cagasan ${ }^{2 *}$,Christina A. Gabrillo ${ }^{2}$ and \\ Milagros C. Bales ${ }^{3}$
}

\begin{abstract}
Submitted: 11 December 2019 | Accepted: 9 June 2020

The Philippines has been implementing its Expanded Program on Immunization (EPI) for over 40 years now. However, measles outbreaks are still reported. One of the reasons behind this is parental vaccine hesitancy. This study aimed to understand conditions surrounding vaccine hesitancy among mothers in San Antonio, Northern Samar where rubella (German measles) outbreak was reported in 2017. A total of 16 mothers and three program implementers served as informants for this study. It was found that despite the communication strategies used by the EPI program implementers, parental vaccine-hesitancy existed in the municipality. The mothers were considered vaccine-hesitant because of their delay in subjecting their children to measles vaccination. Analysis of the interview transcripts using the Grounded Theory approach revealed a number of conditions surrounding vaccine hesitancy among mothers. These include: (1) preoccupation with household responsibilities, (2) misunderstanding of the information on measles vaccination, (3) influence of social networks on vaccination decisions, and (4) negative perceptions about measles vaccination. The mothers' hesitancy to subject their children to measles vaccination caused their children to be infected with the disease, and had resulted in an outbreak of rubella in the community. The rubella outbreak eventually led to vaccine uptake when parents realized the importance of subjecting their children to vaccination and when the government implemented mandatory measles, mumps and rubella (MMR) vaccination.
\end{abstract}

Keywords: Vaccine hesitancy, MMR vaccination, vaccine uptake, EPI program, rubella, measles

\section{INTRODUCTION}

Vaccines for all by 2030. This has been specified in the Sustainable Development Goal (SDG) Number 3 which aims to ensure healthy lives and promote

'Office of the Dean of Graduate School, Visayas State University, Baybay City-6521, Leyte

${ }^{2}$ Department of Development Communication, Visayas State University, Baybay City-6521, Leyte

${ }^{3}$ Department of Agricultural Education \& Extension, Visayas State University, Baybay City-6521, Leyte

*Corresponding Author. Address: Department of Development Communication, Visayas State University, Baybay City-6521, Leyte; Email: edithcagasan@vsu.edu.ph

DOI: $10.32945 /$ atr4229.2020 
well-being for all people at all ages (United Nations 2015). To achieve this goal, health communication has been found very important. According to Rimal and Lapinski (2009) and the Center for Disease Control and Prevention (CDCP 2011), health communication is becoming a known field since it has much to contribute in changing human behavior. Hence, it is now widely used by many health practitioners and program developers, most especially in programs initiated by the government such as immunization programs (CDCP 2011).

In the Philippines, as early as 1976 , the government has already recognized the importance of vaccine-preventable diseases as evidenced by the implementation of the Expanded Program on Immunization (EPI) through Presidential Decree 996. The program aimed to ensure that children, particularly infants, and their mothers have access to vaccines recommended for their age to prevent specific diseases such as measles and rubella (German measles). But according to the World Health Organization [WHO] (2018a), despite the massive health communication campaigns, there are still parents who experience vaccine hesitancy, which refers to the delay in acceptance or the complete refusal of vaccines despite availability of vaccination services (MacDonald 2015). Many parents question whether it is safe and necessary to vaccinate their children (Miller, Verhoef \& Cardwell 2008). Ames, Glenton, and Lewis (2017) also pointed out that some parents do not trust vaccines or the health workers who administer these, so these parents are hesitant to have their children immunized. Thus, measles remains one of the leading causes of preventable death globally among children (WHO 2018a).

Concerned organizations have been exerting efforts to improve immunization rate in the country. In a Department of Health (DOH) report in 2017, however, only about $60 \%$ of Filipino children were getting their scheduled vaccines, despite a target vaccination rate of $85 \%$ (Cepeda 2018). This low vaccination rate was linked to the controversy on Dengvaxia, a dengue vaccine which created massive panic all over the country, especially among parents, towards the end of 2017 (Santos 2018). This phenomenon supports the finding of Al-lela et al (2014) that improvements in immunization rate lies not only on the efforts of the service providers, but also on the parents' decision to have their children vaccinated.

There are already a number of studies about vaccine hesitancy in recent years, but only a few have focused on its underlying causes, especially in the rural areas. Williams (2014) noted that there is a need to understand the underlying conditions influencing vaccine hesitancy to better address the increasing level of vaccine hesitancy among parents. The study of Gowda et al (2013) likewise suggested that vaccine-hesitant parents have a wide-ranging vaccine-specific concerns that need to be addressed effectively at a localized level in order to have positive impacts on parents' vaccination decision-making. There is a need to assess their current perceptions and refute their negative beliefs, through identifying the most effective strategies that can enable health care providers to communicate with vaccinehesitant parents in a more targeted approach. An adequate assessment of the conditions that cause vaccine hesitancy specific in a regional setting (WHO 2018b; Caitlin et al 2015) is needed.

This study sought to understand the conditions surrounding vaccine hesitancy among mothers in San Antonio, Northern Samar where rubella outbreak was declared in 2017. This study is important because results can help health service providers to have a deeper understanding of the parents' perceptions, beliefs, and attitudes toward subjecting their children to measles vaccination. Further, 
Understanding vaccine hesitancy among mothers

results of this study can be used as bases in improving the communication strategies used by the health service providers and health communicators in convincing parents to have their children vaccinated.

\section{METHODOLOGY}

The study was conducted in the barangays of an island municipality of San Antonio, Northern Samar $\left(12.4110^{\circ} \mathrm{N}, 124.2588^{\circ} \mathrm{E}\right)$, namely: Dalupirit, Manraya, Pilar, and Ward III-Poblacion (Figure 1). The municipality was chosen as the study site since according to the DOH (2017) report, it had the highest incidence of Rubella (German measles) with 38 confirmed cases - the highest among other areas of Region 8 . This phenomenon implies high vaccine hesitancy among parents in the area.

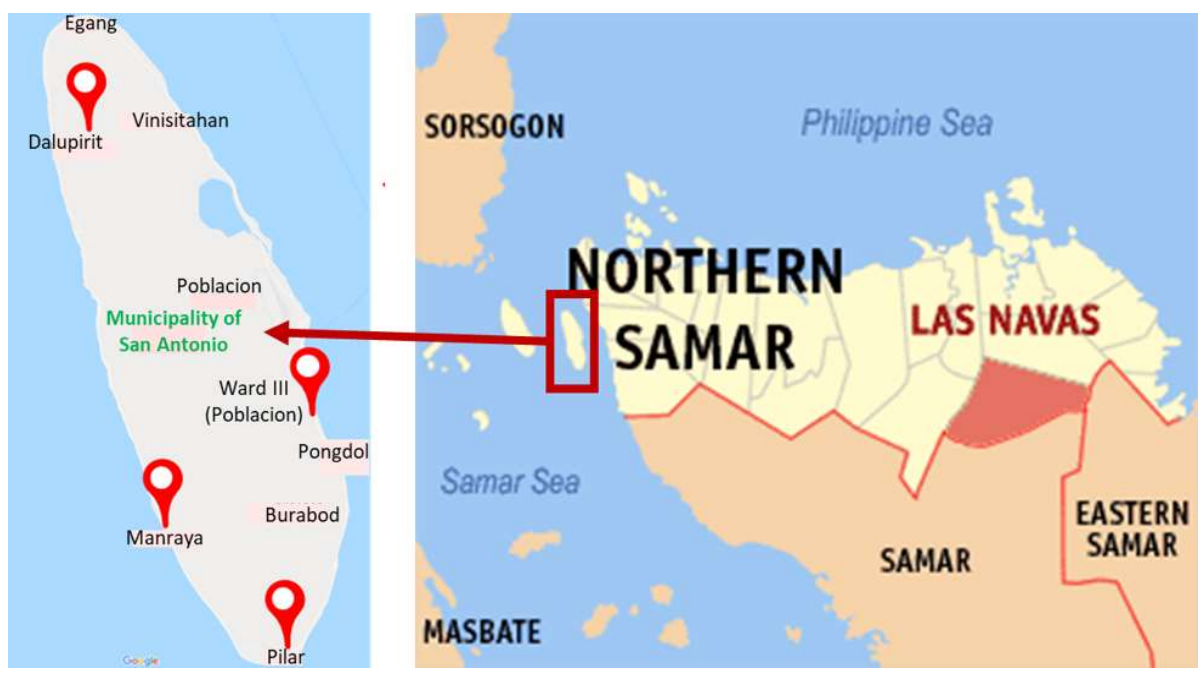

Figure 1. The study sites in Barangay San Antonio, Northern Samar Source: Google Maps

\section{Research Design and Sampling Procedure}

This study aimed to develop a theory on the conditions surrounding vaccine hesitancy among mothers in a village that experienced rubella outbreak, thus it followed the constructivist grounded theory (GT) approach of Charmaz (2006). This GT approach embraces the social constructivist assumptions that there are multiple realities, that researchers are part of the world that they study and the data that they collect, and that grounded theories are not discovered but are constructed through the researchers' "past and present involvements and interactions with people, perspectives, and research practices" (Charmaz 2006 p.10). In this study, the researchers assumed that mothers in San Antonio, Northern Samar had different experiences related to their children's vaccination, and that their vaccination decisions and actions could be informed by their interactions with the 
people and organizations in their community. Also, the researchers acknowledge that their research experiences and theoretical alignment would have some influence on the conceptualization of the study, data collection, data analysis, and the construction of the grounded theory on conditions surrounding vaccine hesitancy among mothers in the study sites. The informants of this study were purposively chosen based on the following criteria: (1) they were identified as vaccine-hesitant parents by the Rural Health Unit (RHU) personnel in-charge with $\mathrm{EPI},(2)$ they were available during the conduct of the study, and (3) they were willing to participate in the study. Informants were identified using the snowball sampling technique. The primary informant was identified with the assistance of the RHU personnel and the barangay health worker. The next informant was identified through a referral by the primary informant. The other informants were then identified using the same referral procedure. The total number of informants was determined through theoretical sampling where selection of informants stopped when theoretical saturation was reached, that is when no more new information or conceptual insights were added to the data (Bloor \& Wood 2006, Kenny \& Fourie 2015).

\section{Data Gathering Procedure}

A methodological triangulation was used to enhance gathering of data on the communication strategies used in the EPI implementation. According to Bekhet and Zauszniewski (2012), triangulation can provide a more comprehensive data, better validity, and understanding of a phenomenon being studied since it applies multiple methods to gather data. This study involved discreet observations on communication materials used and in-depth interviews with program implementers and informants.

The in-depth interview guide for the program implementers focused on the communication strategies they had applied in the EPI program, the challenges they had encountered in using those strategies, and how they resolved the issues. On the other hand, the in-depth interview guide for the mother-informants included questions on the communication strategies used in the DOH immunization program, informants' exposure to information on MMR vaccination, perceptions on MMR vaccination, and reasons for delaying the MMR vaccination of their children.

The informants' answers were recorded using a digital recorder with their permission. These were transcribed verbatim and encoded as a written document. To clarify some of the information gathered during the face-to-face interviews with the informants, follow-up interviews with some informants were done through mobile phone calls. The researchers wanted to go back to the study sites and do face-to-face interviews, but it was not possible due to the bad weather which made travel to the island municipality difficult. According to Şahin and Yan (2013), the use of mobile phone as a tool in research data collection is becoming popular due to its potential to reach the target population even in rural areas. Fitzgerald and FitzGibbon (2014) added that using mobile phone as an information and communication technology (ICT) does not only increase the efficiency of data collection but also reduces research cost due to its affordability nowadays. During the phone interviews, consent was first sought from the informants to put the call on loud speaker and record their responses. Their responses were also transcribed verbatim and were encoded as a written document. 
Understanding vaccine hesitancy among mothers

\section{Data Analysis}

Descriptive statistics including frequency counts, totals, and percentages were used to analyze the informants' socio-demographic characteristics. Data gathered from the interview with the program implementers were analysed through thematic analysis and presented using narrative descriptions.

On the other hand, the data gathered through in-depth interviews about the mother-informants' experiences relating to their children's vaccination were analyzed using the Grounded Theory Approach (GTA) of Charmaz (2006). This GT approach is composed of three steps, namely: 1) initial coding wherein initial categories of information about vaccine hesitancy among mothers were formed by segmenting (word-by-word \& line-by-line) the information taken from the transcribed texts, 2) focused coding wherein the categories formed from initial coding were synthesized so as to determine the adequacy of the codes and to decide "which initial codes make the most analytic sense to categorize the data incisively and completely" (Charmaz 2006 p.58), and 3) theoretical coding wherein the relationships among the categories or codes formed during the focused coding were conceptualized, and a "story line" or theoretical proposition about the conditions surrounding vaccine hesitancy was constructed.

\section{RESULTS AND DISCUSSION}

\section{Description of the Study Site}

San Antonio is a fifth-class municipality in the province of Northern Samar. It is located in the coast of San Bernardino Strait and Samar Sea in the northwest part of the province. In 2017, the municipality of San Antonio declared rubella outbreak. Rubella, also known as German measles, is a milder form of measles which shows milder symptoms including fever and rashes. Yet, it is most risky to pregnant women since it can cause miscarriage or serious birth defects in a developing baby (CDCP 2018).

According to the RHU personnel, the carrier of the disease was a transferee student from Manila who infected most of the Grade 11 students and three teachers in San Antonio Agricultural and Vocational School (SAAVS) located in barangay Dalupirit. One of the teachers was infected during her pregnancy which resulted in a birth defect and eventual death of her three-month old baby.

The rubella outbreak in San Antonio reinforced the findings of Omer et al (2009) that vaccine-preventable disease outbreaks often start with individuals who refused vaccinations. Infection would then rapidly spread within an unvaccinated population.

\section{Description of the Informants}

\section{The mother-informants}

Socio-demographic characteristics. There were 16 mother-informants in the study whose primary language is Cebuano despite being located in a Warayspeaking province due to the large number of migrants from Cebu and Bohol 
(Marcuap 2014). Most of them depend on their husbands to provide for their families' daily needs. The husbands' occupations include fishing and driving a passenger motorcycle (locally-termed as habal-habal) or pump boat as public transportation modes. For this reason, the fathers were not present during the datagathering; hence, only the mothers became informants of this study.

The researchers believed that it was alright to only interview the mothers since according to Erci et al (2016), they are primarily responsible for making decisions regarding their child's health. Most of them had one to six years of schooling $(56.25 \%)$, others reached high school (37.50\%), and one had no schooling at all $(6.25 \%)$. Half of the informants (50\%) had five children and below, while the other half (50\%) had six children and above.

Measles vaccination practices. Since the rubella outbreak in 2017, the RHU intensified the implementation of EPI in the municipality of San Antonio. Thus, during the conduct of the study, the 16 informants reported that their children were already vaccinated with MMR vaccine due to a mandatory vaccination initiative of their RHU. However, the RHU personnel and local health workers classified these mothers as vaccine-hesitant parents because they either refused or delayed the MMR vaccination of their children before the rubella outbreak. Dubé et al (2013) defined vaccine hesitancy as the refusal or the delay of acceptance of the vaccine despite the availability of free immunization services. In this study, 11 of the mother-informants had children aged 16 to 18 years old who were infected with rubella. This suggests that they got their children vaccinated with MMR only after the rubella outbreak. The rest of the mother-informants had delayed the vaccination schedule for their children for about three to five months according to RHU records.

\section{The Program Implementers}

A total of three program implementers were asked about the communication strategies used in EPI implementation. One was an RHU midwife who was a former coordinator of the EPI program, one was a Barangay Nutrition Scholar (BNS), and one was a Barangay Health Worker (BHW). All were female and middle-aged.

\section{Mother-informants' Health Information Seeking Behavior}

All of the mother-informants said that they seek health information. However, they do it only when they are confronted with an illness. Most of them said that they access health information from the RHU personnel and from radio, specifically from the Radyo Natin station in Calbayog City and the Super Radyo station broadcasting from Cebu City. Some even access health information from the internet using their smart phones. Only a few of them have access to television since most of the informants do not own a set.

\section{Awareness About Measles Vaccination Program}

According to the program implementers and the mother-informants, the communication strategies used in disseminating information on the MMR vaccination include: bandillo (oral announcement done by a town crier), interpersonal communication, and posters. 
Understanding vaccine hesitancy among mothers

Narratives of the mother-informants revealed that all of them were aware about the government's program on measles vaccination in general. However, only a few knew specifically about the MMR vaccine. They have acquired this information from the bandillos in their barangays, the RHU personnel, Barangay Nutrition Scholar (BNS), and the Barangay Health Workers (BHWs). The information they obtained was basically a reminder to vaccinate their children.

Some of the mother-informants said that they knew only about the vaccination against measles. Although they claimed that their children had complete vaccination, they did not know specifically that the second vaccination schedule was for the MMR vaccine. This suggests that although they were exposed to information on measles vaccination, they lacked specific knowledge about the vaccines that were given. Informant 13 , for instance, said:

“Wala man ko kabalo anang sa MMR. Basta kay kompleto na sila sa bakuna kontra tigdas...niari ra man 'tong taga $R H U$, gi bakunahan akong bata" (I don't know what MMR is. But I know that they are complete with vaccination against measles...the RHU personnel came and vaccinated my child.)

\section{Perceptions about MMR Vaccination and the Government's Immunization Program}

Since this study was conducted months after the rubella outbreak, it was found that all the mother-informants had already subjected their children to MMR vaccination because of the mandatory measles vaccination. Hence, the perceptions of the mother-informants about the MMR vaccination, and the immunization program in general, before and after the rubella outbreak were sought to have a better understanding of the conditions surrounding vaccine hesitancy.

\section{Perceptions on Measles Vaccination before the Rubella Outbreak}

When the mother-informants were asked what they thought about the MMR vaccine and the government's immunization before the rubella outbreak in their municipality, two themes emerged from their responses. These include: (1) vaccination is unsafe for their children, and (2) vaccination is not that important for their children's health.

Vaccination is unsafe for their children. Some of the mother-informants narrated that before the rubella outbreak, they thought that the vaccine for measles is unsafe for their children. An informant said that she decided not to subject her child to measles vaccination because there is a chance that she would get sick after being vaccinated. This suggests that some mothers were hesitant to subject their children to vaccination because they feared about the risk associated with vaccination. According to Informant 5 ,

"Katong una jud dili ko ana kumpyansa sa bakuna sa tigdas kay magkasakit man kuno ang bata inig human. Mao to abi nako og mas delikado hinuon sa akong bata og ako pabakunahan." (At first, I was not 
confident to subject my child to measles vaccination because they said that he will get sick after. That is why I thought it will be more dangerous if my child would be vaccinated.)

This perception that "vaccination is unsafe for their children" falls under the confidence category in the " $3 \mathrm{Cs}$ " model of Vaccine Hesitancy that was first proposed to the WHO EURO Vaccine Communications Working Group (MacDonald 2015 p.2). As explained in the "3 Cs" model, vaccine hesitancy may occur when there is lack of trust "in the effectiveness and safety of vaccines, the system that delivers them, and in the motivations of the policy-makers who decide on the need of the vaccines" (MacDonald 2015 p.2).

Vaccination is not that important for their children's health. Some of the informants also said they thought that measles vaccination is not that important for their child's health. For instance, according to Informant 12,

"Bago niato, wala ra jud ko kay abe man nako kanang dili ra kaayo importante sa bata ... naa bitaw uban ngare sa amo di man sad pabakuna sa una" (Before [the outbreak], I just did not mind [subjecting my child to measles vaccination] because I thought it was not that important for my child ... even my neighbors would not also subject their children to [measles] vaccination before.)

This perception that "vaccination is not that important in their children's health" falls under the complacency category in the " $3 \mathrm{Cs}$ " model of Vaccine Hesitancy. As pointed out by MacDonald (2015), vaccine complacency occurs when "perceived risks of vaccine-preventable diseases are low" and child carers do not consider vaccination as an important preventive action.

The abovementioned perceptions also imply that mothers' vaccination decisions could be influenced by their peers and neighbors who are part of their social network. These results conform to the findings of Brunson (2013) that the influence of social networks greatly contributes to the decision-making of a parent about his or her child's vaccination.

\section{Perceptions after the Outbreak}

After the rubella outbreak in the community, the mother-informants' perceptions about the immunization program of the government in general, and the MMR vaccination in particular, have changed. The mothers perceived the vaccinations to be beneficial because of the following reasons: (1) vaccination is good for their children's health, and (2) vaccines are free which is favorable for them as well.

Vaccination is good for their children's health. Some of the mother-informants realized that the MMR vaccine is, after all, good for their children's health. This realization came when the mothers actually witnessed the negative consequence of not subjecting their children to measles vaccination. For instance, Informant 1 said: 
Understanding vaccine hesitancy among mothers

"Gipabakunahan na nako ako mga anak arun dili na sila matakdan ug tigdas...Oo, importante man na siya." (I have already subjected my children to measles vaccination so that they will not be infected with measles... Yes, it [MMR vaccine] is important.)

Vaccines are favorable since they are given free. Another informant said that the MMR and other vaccines are beneficial for them since they do not have to pay for these because they are provided by the government for free. She said,

"Aw libre na siya nga bakuna gihatag diri sa amo mga bata... Oo, maayo nalang wala mi gastohan para ana." (It is a free vaccine provided to our children ....yes, it is good since we do not have to pay for it.)

This finding supports the proposition of the " $3 \mathrm{Cs}$ " model of Vaccine Hesitancy which posits that vaccination convenience, which comprises physical availability and affordability of vaccines, among others, can affect the uptake of immunization or vaccination services (MacDonald 2015).

\section{Conditions Leading to Vaccine Hesitancy among the Mother-Informants}

Analysis of the mother-informants' narratives revealed four themes representing their reasons for delaying the MMR vaccination of their children (Table 1). The reasons include: (1) preoccupation with household responsibilities, (2) misunderstanding of the information on measles vaccination, (3) influence of social networks on vaccination decisions, and (4) negative perceptions about measles vaccination.

Table 1. Conditions that surround vaccine hesitancy among mothers

\begin{tabular}{ll}
\hline \multicolumn{1}{c}{ Themes } & \multicolumn{1}{c}{ Description } \\
\hline $\begin{array}{l}\text { Preoccupation with household } \\
\text { responsibilities }\end{array}$ & $\begin{array}{l}\text { Most of the informants were housewives; hence, they said that } \\
\text { they were not able to bring their children to RHU for measles } \\
\text { vaccination because they were preoccupied with household } \\
\text { chores and their responsibilities as care providers for their } \\
\text { children. }\end{array}$ \\
$\begin{array}{ll}\text { Misunderstanding the information } \\
\text { Some of the informants did not fully understand how } \\
\text { vaccination against measles works. }\end{array}$ \\
$\begin{array}{ll}\text { Influence of social networks on } \\
\text { mothers' vaccination decisions }\end{array}$ & $\begin{array}{l}\text { Some of the informants revealed that their decision not to } \\
\text { subject their children for vaccination was influenced by their } \\
\text { social networks such as their relatives and neighbors. }\end{array}$ \\
Negative perceptions about & $\begin{array}{l}\text { Before the rubella outbreak, the mother-informants had negative } \\
\text { measles vaccination }\end{array}$ \\
$\begin{array}{l}\text { Vaccination is not safe for their } \\
\text { to subject their children to measles vaccination. } \\
\text { children } \\
\text { Vaccination is not that important } \\
\text { for their children's health }\end{array}$ & $\begin{array}{l}\text { Some informants believed that vaccines are risky because it can } \\
\text { make their children sick. } \\
\text { Some informants said that subjecting their children to MMR } \\
\text { vaccination is not that important. }\end{array}$ \\
\hline
\end{tabular}


Ogalesco et al

\section{Preoccupation with Household Responsibilities}

Some of the mother-informants reasoned that sometimes, they could not follow the vaccination schedule for their children because they were either preoccupied with household chores or nobody else would take care of their other children since their husbands are busy making a living. Informant 6 , for instance, said:

"Dili man madala ma'am uy, usahay walay bantay sa akong mga bagsok. Magdung-ag pa ko, manglaba. Maayo ra unta og bawod ang dagat kay dia ako bana sa balay mubantay, makaadto jud ko sa center dala sa ako bata. "(It would be impossible Ma'am [to be on schedule with the child's vaccination] because there are times that no one else is here to take care of the children. I have to cook, wash the clothes. It would have been better if the sea is rough because my husband would be here to take care of the other children, so I can bring my [little] child to the center for his vaccination schedule).

This result was also evident in the study of Kagone et al (2018) in the rural area of West Africa. They found that mothers tend not to follow the vaccination schedule of their children because they were busy with their household work.

\section{Misunderstanding of the Information about the Vaccination}

Some of the mother-informants' responses implied that they have misunderstood the information given to them about vaccination against measles. Informant no. 14 said:

"Nadugay ko pagpabakuna sa akong anak para MMR kay abi nako usa ra ang bakuna kontra sa tigdas. Naa pa diay ikaduha. ... Katong una? Oo, ako to siya napabakunahan.." (The MMR vaccination of my child was delayed because I thought that there was only one vaccination against measles. I learned there is still a second dose...The first? Yes, I was able to have my child vaccinated.)

Misunderstanding of information about vaccination may be related with the mother-informants' educational attainment. More than half of mother-informants only had one to six years of schooling. According to Palmer and McNeill (2009), the education of the parents acts as a go-between with their children's health and vaccination status. Thus, their level of education is associated with their misunderstanding of the information regarding the vaccines and how important it is to follow the recommended schedule. This implies the importance of a tailored information campaign strategy that is well-suited to their needs. 
Understanding vaccine hesitancy among mothers

This result also supports the findings of other researchers that misunderstanding of vaccination information contributes greatly to vaccine hesitancy or delay in vaccine uptake. According to Dubé et al (2014), parents must be properly informed of the recommended vaccination schedule of their children and the importance of following such schedule, so that they can act as desired, otherwise it would result to the delay or refusal of the parents to subject their children to vaccination.

\section{Influence of Social Networks to Parents' Vaccination Decisions}

It was revealed from the responses of the mother-informants that their decision not to subject their children to vaccination was influenced by their social networks such as relatives and neighbors. An informant narrated that her old relatives had a pre-existing belief that if a child is subjected to vaccination, he or she would get ill. She was afraid that the same thing would happen to her child, thus resulting to risk avoidance. She decided not to subject her child to measles vaccination. According to Informant no. 5,

"Ang mga katigulangan niadto dili pabakunahan ang ila anak kay ingun pa nila grabe kuno ang hilanat inig human bakuna... Ambot lang pud nila, mituo na lamang sad ko niatong mga panahona." (In the past, our old relatives did not get their children vaccinated because according to them the child would usually suffer from high fever after being vaccinated. I don't know, I just believed them and did not subject my child to measles vaccination during those times.)

According to CDCP (2018), since measles vaccination includes introduction of very small doses of MMR viruses to children to enable their body system to develop antibodies, a very mild form of measles may be experienced one to two weeks after vaccination.

The other mother-informants also implied that they decided not to vaccinate their children because of the influence of their neighbors. Informant no. 12, for instance, said:

“...Oo kay wala ra man sad sila. Wala ra sad ko nagpabakuna sa akong anak. Abi man nako og okay ra dili lang usa magpabakuna" (...Yes, because they [my neighbors] just did not care [to subject their children to measles vaccination]. So, I decided not to subject my child to [measles] vaccination also. I thought before that it is okay to delay the vaccination of my child.)

The abovementioned statements further support the findings of Brunson (2013) that the behavior of a social network on a recommended vaccine can influence not only the parents' vaccination decisions but also their perceptions about vaccination. 
Ogalesco et al

\section{Negative Perceptions About Measles Vaccination}

As mentioned earlier, the social networks of the mother-informants did not only influence their vaccination decisions, but also their perceptions on the measles vaccine. Their perceptions on the measles vaccination before the rubella outbreak were all negative, and this influenced their decision not to subject their children to measles vaccination because they thought that it could do more harm than good, and they did not see its importance at that time.

These perceptions were also indicated in the study of Saada et al (2015) that some parents who were vaccine-hesitant believed that if the disease is not prevalent, there is a minimal risk for their children catching the disease, and thus they do not consider the importance of vaccination. Moreover, the parents believed that the possible side effects of the vaccines are greater than the benefits these can give their children (McKee \& Bohannon 2016).

\section{Outcomes of Vaccine Hesitancy}

The mother-informants' narratives revealed that the delayed or incomplete measles vaccination of the children caused them to be infected with rubella disease and led to the declaration of rubella outbreak in their municipality.

\section{Child caught rubella disease}

Some of the informants expressed that because they have delayed the vaccination for their children, they exposed them to the disease and their children suffered from fever and rashes. Informant no. 8 said:

“...mao to siya ma'am. Natakdan jud siya sa tigdas. Grabe iya lawas ato daghan puwa puwa ug grabe ang hilanat" (...that was it ma'am. My child caught [rubella] measles. Her body got rashes and she had high fever.)

\section{Outbreak was declared in the municipality}

An informant mentioned that many of her child's classmates were also infected because they were also not vaccinated. Informant no. 15 said:

"...daghan to sila natakdan. lya ra pud mga classmates. Mao to nag outbreak mi diria". (...many were infected [with rubella]. They were her classmates. That's why [rubella] outbreak was declared here [in our municipality].)

This outcome supports the findings of Omer et al (2009) that vaccine hesitancy does not only increase the health risk of a person but also the health risk of the community as a whole.

\section{Consequence of the Rubella Outbreak}

After the outbreak was declared in their municipality, the mother-informants became aware of the risk of delaying or not subjecting their children to measles 
Understanding vaccine hesitancy among mothers

vaccination. It eventually resulted in the change of their perception regarding the importance of complete measles vaccination. The mothers with children who were infected with the rubella disease admitted that after seeing their children suffer from the infection, they realized the importance of complete measles vaccination for their children. According to Informant no. 10:

"Sukad atong nagkasakit ako anak ma'am ako na man to gisiguro kumpleto sa bakuna iya mga manghud..." (After one of my children got measles, I made sure that her younger siblings get complete vaccination.)

Informant no. 8 added that she regretted not being able to get the vaccination for her child. She said,

“...nagbasol ko ma'am ato...nakaingon ko importante jud bakuna para sa bata. Kung napabakunahan, wala unta matakdi" (I regretted that I wasn't able to get my child vaccinated against measles. I realized it was very important. If she was only vaccinated, she would not have gotten the disease.)

Additionally, the outbreak in the municipality also resulted in a mandatory measles vaccination initiated by the RHU personnel. This initiative involved rigorous monitoring of children vaccination schedule and house-to-house visits once vaccine hesitancy was found.

\section{General Proposition on the Conditions Surrounding Vaccine Hesitancy among Mothers}

Figure 2 presents the conditions surrounding vaccine hesitancy and vaccine uptake among the vaccine-hesitant mothers in San Antonio, Northern Samar.

The mothers became aware of the vaccination program of the government through the communication strategies used by the EPI implementers in disseminating information regarding the MMR vaccine schedule. The communication strategies used included: (1) bandillo, (2) interpersonal communication through their RHU personnel, BNS and BHWs, and (3) the use of posters. Despite the information dissemination efforts of the program implementers, some mothers were hesitant to subject their children to vaccination. Their hesitancy, which caused incomplete or delayed vaccination of their children, was due to one or a combination of the following reasons: (1) preoccupation with household responsibilities, (2) misunderstanding of the information about measles vaccination, (3) influence of social networks on parents' vaccination decisions, and (4) negative perceptions about measles vaccination.

The incomplete or delayed measles vaccination of the children of the vaccinehesitant mothers led to the following outcomes: (1) their children caught the rubella disease, and (2) rubella outbreak was declared in their municipality. The mothers' experience of having their children infected with the rubella measles and the declaration of measles outbreak in their locality resulted in a change of the mothers' perceptions on the importance of measles vaccination and into vaccine uptake among the vaccine-hesitant mothers. 


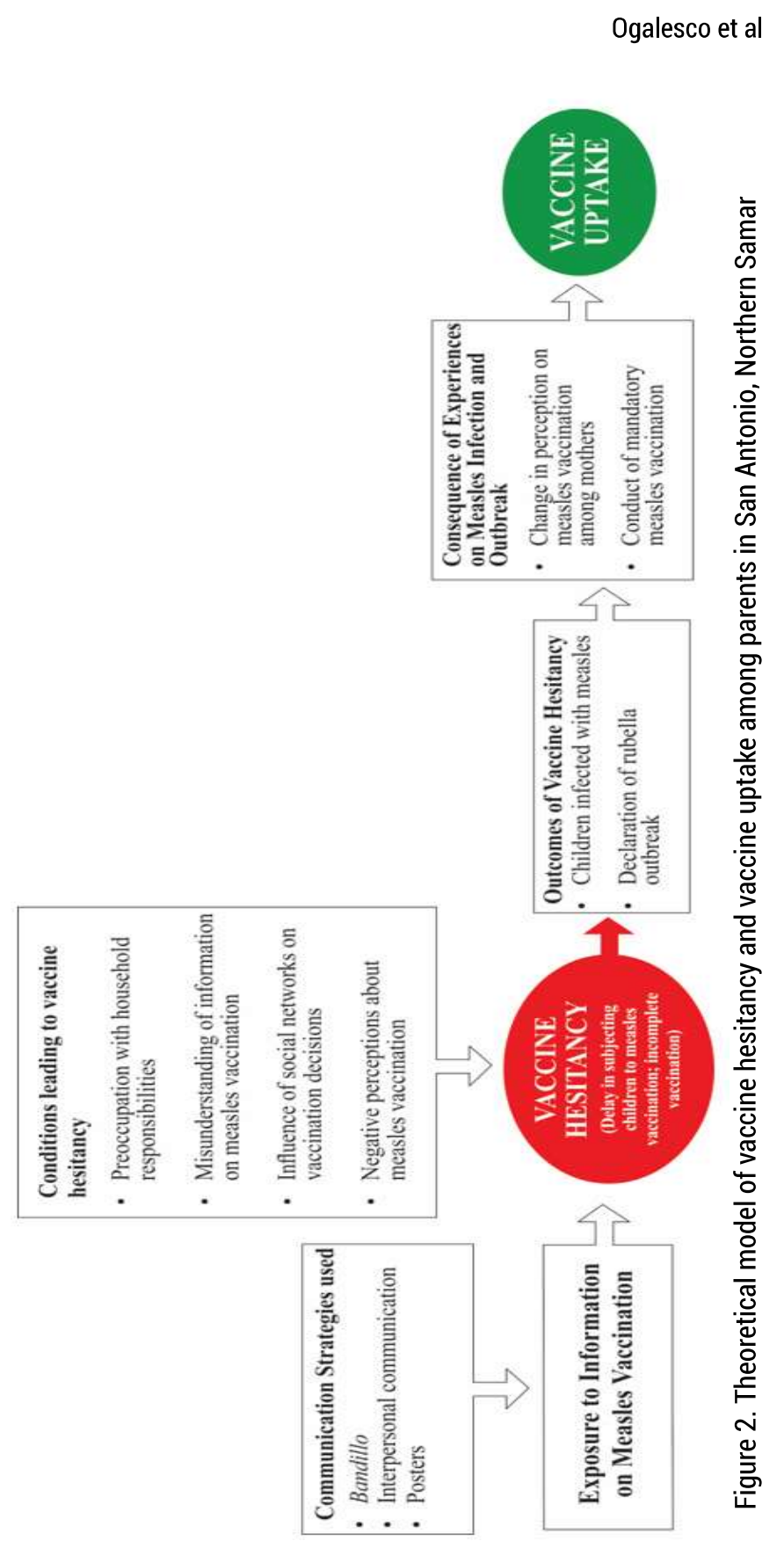


Understanding vaccine hesitancy among mothers

\section{IMPLICATIONS AND RECOMMENDATIONS}

This study revealed that vaccine hesitancy was evident in San Antonio, Northern Samar despite the mother-informants' awareness of the measles vaccination program in general. The mothers were classified as vaccine-hesitant parents since they had delayed the vaccination of their children for some reasons.

One of the conditions causing vaccine hesitancy was the mothers' being overloaded with household chores. The delay in vaccination due to preoccupation with household chores can be related to the mothers' socio-demographic characteristics. In this study, half of mother informants had six children and above, which made them too preoccupied with their household responsibilities such as taking care of their children, and doing chores such as laundry and cooking. This finding supports the explanation put forward by the "3 Cs" model of vaccine hesitancy which says that complacency about vaccination is influenced by a number of factors which include being busy with other responsibilities that are considered more important at a particular time (MacDonald 2015). In the case of the mothers in this study, doing household chores was considered more important than subjecting their children to vaccination.

The decision to delay or forego vaccination in favor of performing household chores can also be taken as an indication that the mother-informants did not consider vaccination of their children as a main concern or of prime importance prior to the rubella outbreak. If they were convinced about the importance of on-time measles vaccination, they could have taken the initiative to take their children to the RHU for vaccination. This finding suggests the need for health authorities to devise a mechanism to ensure that mothers subject their children to vaccination on time. Included in this mechanism may be the training and deployment of local health workers who could encourage parents to subject their children to vaccination on time, or even to visit the home of vaccine-hesitant parents to administer vaccine to their children on schedule.

Another condition that led to vaccine hesitancy among mothers in this study was their negative perceptions of measles vaccination. This negative perception appeared to have been influenced by the information obtained by mothers through their social networks, a situation that was evident in the previous studies on vaccine hesitancy (Kagone et al 2018, Palmer \& McNeill 2009, Dubé et al 2014, Saada et al 2015, McKee \& Bohannon 2016). Many of the mother-informants in this study said they were told by their friends and relatives that vaccination is not that important and could make their children sick; that is why they refused to subject their children to vaccination. This finding highlights the need for an effective communication intervention, like the conduct of a monthly health information seminar, to correct misperceptions and negative beliefs about vaccination among mothers.

Overall results of this study suggest the need to design a strategic communication campaign to reduce rate of vaccine hesitancy among parents. In this campaign, messages should be strategically positioned and should employ appropriate communication channels to send the vaccine messages to the parents. For example, given that the mothers' vaccine uptake was mainly influenced by their experiences of the consequences of delaying their children's vaccination and the mandatory measles vaccination conducted by the LGU, it is only logical that the fear 
appeal strategy be applied in explaining the consequences of non-compliance to the recommended health practice. Likewise, since LGUs are perceived as credible, they can develop and implement a policy on mandatory measles vaccination for children.

As with other rural communities, in the study sites, face-to-face information in the form of house visits by local health workers was considered by the mothers as the most effective communication strategy to convince parents to subject their children to on-time vaccination. This finding confirms the observation of Wittels (2016) and undescores the need for community health workers for a successful health communication campaigns.

Based on some criteria, the measles vaccination campaign in San Antonio, Northern Samar can be judged as successful. Thus, the strategies applied in the sites of the present study may also be used by health workers in implementing campaigns to address vaccine hesitancy in other communities. Among other things, the strategies need to include close monitoring of any sign of delay on the children's vaccination and immediately visiting the household once vaccine hesitancy is detected. Parents should be made to understand the risks of delayed or no vaccination and the importance of on-time vaccinations.

Findings related to health information seeking behavior emphasize the need to intensify campaigns about other illnesses. This idea is anchored on the finding that mothers in this study tend not to seek health information to prevent a disease; instead, they only seek health information when they are faced with an illness. It is, therefore, important that proactive health information dissemination activities for parents in rural areas be designed. Among the communication channels that should be tapped for this initiative are the rural health workers who are considered reliable source of health information by the local people.

More studies need to be conducted to improve our understanding on the conditions that encourage and discourage parents to subject their children to vaccination. Future studies may focus on the decision-making process involved in subjecting children to vaccination. A quantitative study can also be conducted to find out the influence of parents' socio-demographic characteristics on their decision to subject their children to vaccination. Since most households in the rural areas now own cellular phones, it may also be interesting to study if ICTs can be effectively used as a means for reminding parents of their children's vaccination schedule.

\section{REFERENCES}

Al-lela OQB, Bahari MB, Salih MRM, Al-abbassi MG, Elkalmi RM \& Jamshed SQ. 2014. Factors underlying inadequate parents' awareness regarding pediatrics immunization: Findings of cross-sectional study in Mosul-Iraq. BMCPediatrics 14(1):29

Ames HMR, Glenton C \& Lewin S. 2017. Parents' and informal caregivers' views and experiences of communication about routine childhood vaccination: a synthesis of qualitative evidence. Cochrane Database of Systematic Reviews 2017(2):CD011787

Bekhet A and Zauszniewski J. 2012. Methodological triangulation: An approach to understanding data. Nurse Researcher 20(2):40-43 
Understanding vaccine hesitancy among mothers

Bloor M and Wood F. 2006. Keywords in qualitative methods: A vocabulary of research concepts (pp164-166). Sage Publications, Thousand Oaks, CA

Brunson E. 2013. The impact of social networks on parents' vaccination decisions. Pediatrics 131(5):1397-1404

Caitlin J, Wilson R, O'Leary M, Eckersberger E \& Larson H. 2015. Strategies for addressing vaccine hesitancy: A systematic review. Vaccine 33(34):4180-4190

Centers for Disease Control and Prevention (CDCP). 2018. Measles, Mumps, and Rubella Diseases and How to Protect Against Them. https://www.cdc.gov/vaccinesafety/vaccines/mmr-vaccine.html

Cepeda M. 2018. Kids' vaccination rate down to $60 \%$ after Dengvaxia scare - DOH. Retrieved from Rappler: https://www.rappler.com/nation/195101-kidsvaccination-rate-down-dengvaxia-scare-doh

Charmaz K. 2006. Constructing grounded theory: A practical guide through qualitative analysis. Sage Publications, London, UK

Department of Health (DOH). nd. Expanded Program on Immunization. Retrieved from Department of Health: https://www.doh.gov.ph/expanded-program-onimmunization

Department of Health (DOH). 2017. Measles-Rubella Cases. Retrieved from Department of Health: https://www.doh.gov.ph/sites/default/files/statistics/ 2017\%20Measles\%20Morbidity\%20Week\%201-44.pdf

Dubé E, Laberge C, Guay M, Bramadat P, Roy R \& Bettinger J. 2013. Vaccine hesitancy. Human Vaccines \& Immunotherapeutics 9(8):1763-1773

Dubé E, Gagnon D, Nickels E, Jeram S \& Schuster M. 2014. Mapping vaccine hesitancy--country-specific characteristics of a global phenomenon. Vaccine 32(49):6649-6654

Erci B, Polat S \& Ozyazicioglu N. 2016. Mothers' decision-making processes regarding their children's health care. International Journal of Caring Sciences 9(3):792-800

Fitzgerald $\mathrm{G}$ and FitzGibbon M. 2014. A comparative analysis of traditional and digital data collection methods in social research in LDCs - Case studies exploring implications for participation, empowerment, and (mis)understandings. In IFAC 2014. Proceedings of the 19th World Congress of the International Federation of Automatic Control, Cape Town, South Africa. August 24-29, 2014

Gowda C, Schaffe SE, Kopec K, Markel A \& Dempsey A. 2013. Does the relative importance of MMR vaccine concerns differ by degree of parental vaccine hesitancy? Human Vaccines and Immunotherapeutics 9(2):430-436

Kagone M, Ye M, Nebie E, Sie A, Muller O \& Beiersmann C. 2018. Community perception regarding childhood vaccinations and its implications for effectiveness: A qualitative study in rural Burkina Faso. BMC Public Health 18:324

Kenny M and Fourie R. 2015. Contrasting Classic, Straussian \& Constructivist Grounded Theory: Methodological and philosophical conflicts. The Qualitative Report 20(8):1270-1289

MacDonald NE. 2015. Vaccine hesitancy: Definition, scope and determinants. Vaccine 33(34):4161-4164 
Marcuap HL. 2014. Visiting These 3 "Secret" Towns In Northern Samar Will Leave You Speechless. https://wondersofnorthernsamar. wordpress.com/2015/03/05/top-destinations/

McKee $\mathrm{C}$ and Bohannon K. 2016. Exploring the Reasons Behind Parental Refusal of Vaccines. The Journal of Pediatric Pharmacology and Therapeutics 21(2):104-109

Miller NK, Verhoef M \& Cardwell K. 2008. Rural parents' perspectives about information on child immunization. Rural and Remote Health 8(2):863

Omer S, Salmon D, Orenstein W, deHart P \& Halsey N. 2009. Vaccine refusal, mandatory immunization, and the risks of vaccine-preventable diseases. The New England Journal of Medicine 360(19):1981-1988

Palmer S and McNeill R. 2009. Socio-demographic variables and parental decisionmaking about childhood vaccines - is education more important than deprivation? Tumana Research 1-13

Rimal RN and Lapinski MK. 2009. Why health communication is important in public health. Bull World Health Organ 87:247-248

Saada A, Lieu T, Morain S, Zikmund-Fisher B \& Wittenberg E. 2015. Parents' choices and rationales for alternative vaccination schedules: A qualitative study. Clinical Pediatrics 54(3):236-243

Şahin F and Yan Z. 2013. Mobile phones in data collection: A systematic review. International Journal of Cyber Behavior, Psychology and Learning 3(3):67-87

Santos AP. 2018. Dengue vaccine controversy sparks panic in Philippines. Retrieved from Deutsche Welle: http://www.dw.com/en/dengue-vaccinecontroversy-sparks-panic-in-philippines/a-42711828

United Nations (UN). 2015. Transforming our world: The 2030 agenda for sustainable development. Retrieved from United Nations: https://sustainabledevelopment.un.org/content/documents/21252030\%20A genda\%20for\%20Sustainable\%20Development\%20web.pdf

Williams S. 2014. What are the factors that contribute to parental vaccine-hesitancy and what can we do about it? Human Vaccines \& Immunotherapeutics 10(9):2584-2596

Wittels A. 2016. Exploring the role of communication in community health in sierra leone. BBCMedia Action

World Health Organization (WHO). 2018a. Measles. Retrieved from World Health Organization: http://www.who.int/news-room/fact-sheets/detail/measles

World Health Organization (WHO). 2018b. Addressing Vaccine Hesitancy. Retrieved from World Health Organization. http://www.who.int/ immunization/programmes_systems/vaccine_hesitancy/en

World Health Organization (WHO). nd. SDG 3: Ensure healthy lives and promote well being for all at all ages. https://www.un.org/sustainabledevelopment/health/ 